\title{
Dihydrogen Bond in the Aminoborane Complex of a Nicergoline Intermediate
}

\author{
Jan Čejka ${ }^{1, * \mathbb{D}}$, Ladislav Cvak ${ }^{2}$, Simona Žižková ${ }^{1}$, Bohumil Kratochvíl ${ }^{1}$ and Alexandr Jegorov ${ }^{2,3}$ \\ 1 Department of Solid State Chemistry, University of Chemistry and Technology Prague, Technická 5, \\ 16628 Prague 6, Czech Republic \\ 2 Teva Czech Industries s.r.o., Research and Development, Ostravská 29, 74770 Opava-Komárov, \\ Czech Republic \\ 3 Teva Czech Industries s.r.o., Research and Development, Branišovská 31, 37005 České Budějovice, \\ Czech Republic \\ * Correspondence: Jan.Cejka@vscht.cz; Tel.: +420-702-909-061
}

Academic Editor: Josef Jampilek

Received: 28 May 2019; Accepted: 3 July 2019; Published: 12 July 2019

\begin{abstract}
An aminoborane side product from the nicergoline manufacture process was identified by single-crystal X-ray diffraction. As boranes of pharmaceutical molecules are quite rare, the binding potential of the $\mathrm{BH}_{3}$ group was investigated and compared with similar compounds using Cambridge Structural Database (CSD). Surprisingly, the packing was stabilized by a dihydrogen bond, which triggered a false alert for too-short contact of hydrogen atoms in IUCR checkCIF. As the dihydrogen bond concept is not widely known, such an alert might mislead crystallographers to force $-\mathrm{CH}_{3}$ optimal geometry to $-\mathrm{BH}_{3}$ groups. The $\mathrm{B}-\mathrm{H}$ distances equal to or less than $1.0 \AA$ ( $17 \%$ of the CSD structures) are substantially biased when analyzing the structures of aminoborane complexes in CSD. To conduct proper searching, B-H bond length normalization should be applied in the CSD search.
\end{abstract}

Keywords: nicergoline; aminoborane; CSD; single crystal; X-ray structure; dihydrogen bond

\section{Introduction}

Sodium borohydride is widely used as a reducing agent in the synthesis of many active pharmaceutical substances. By contrast, the possibility that a reaction could be accompanied by the formation of a boron-containing side product is not usually considered. In the course of the reaction of daunomycin with sodium borohydride, various borate esters were observed. In this case, the coordination of boron to the drug proceeded via an oxygen atom [1]. For a number of other sodium borohydride-mediated reactions, the formation of borate esters was also observed [2].

Aminoboranes [3] are usually known as hydrogenation agents. They offer some advantages over sodium borohydride, such as good solubility in organic solvents. They are less sensitive to acids and can serve as chiral reducing agents [4-6]. On the other hand, they are generally weaker reducing agents. Despite their popularity, very few crystal structures of boranes of alkaloids or pharmaceutical molecules have been described. As a rare example, the crystal structures of several borane complexes of cinchona alkaloids have been reported [7].

During the years 1984 and 1985, we were developing a process for the manufacture of nicergoline (1). The process involved the reduction of ester $\mathbf{2}$ to alcohol $\mathbf{3}$ (Figure 1). For safety reasons, we avoided the utilization of $\mathrm{LiAlH}_{4}$ and developed the reduction with $\mathrm{NaBH}_{4}$ in methanol and/or ethanol. During the development of the process, we observed the formation of a lipophilic side product in the reaction mixture. However, the product disappeared during the standard workup: the addition of water, evaporation of methanol and/or ethanol, and isolation of crystalline alcohol $\mathbf{3}$ from aqueous solution. 
<smiles>CO[C@]12C[C@H](COC(=O)c3cncc(Br)c3)CN(C)[C@H]1Cc1cn(C)c3cccc2c13</smiles>

1<smiles>CN[C@@H]1Cc2cn(C)c3c2[C@@H](C[C@@H]1C(=O)OC)C(OC)=CC=C3</smiles>

2<smiles>CO[C@]12C[C@H](CO)CN(C)[C@H]1Cc1cn(C)c3cccc2c13</smiles>

3

Figure 1. Scheme of nicergoline (1), ester (2), and alcohol (3-MeLuol) intermediates.

After the reduction, when the reaction mixture was worked up by partitioning between dichloromethane and water, the lipophilic side product remained in solution. It was isolated by chromatography of the dichloromethane phase and consequent crystallization from toluene. However, at that time, we were not able to reveal its structure when using NMR and MS. As the impurity was not present in the produced alcohol 3, we abandoned our pursuit. At that time, the NMR identification failed because the potential presence of boron was not considered, and further attempts were unsuccessful.

We have thus reinvestigated this side product and decided to determine its structure using X-ray diffraction. X-ray structure determination was chosen because of "its power to show totally unexpected and surprising structure with, at the same time, complete certainty" [8]. And indeed, structure determination revealed the unexpected presence of boron, Figures 2 and 3.
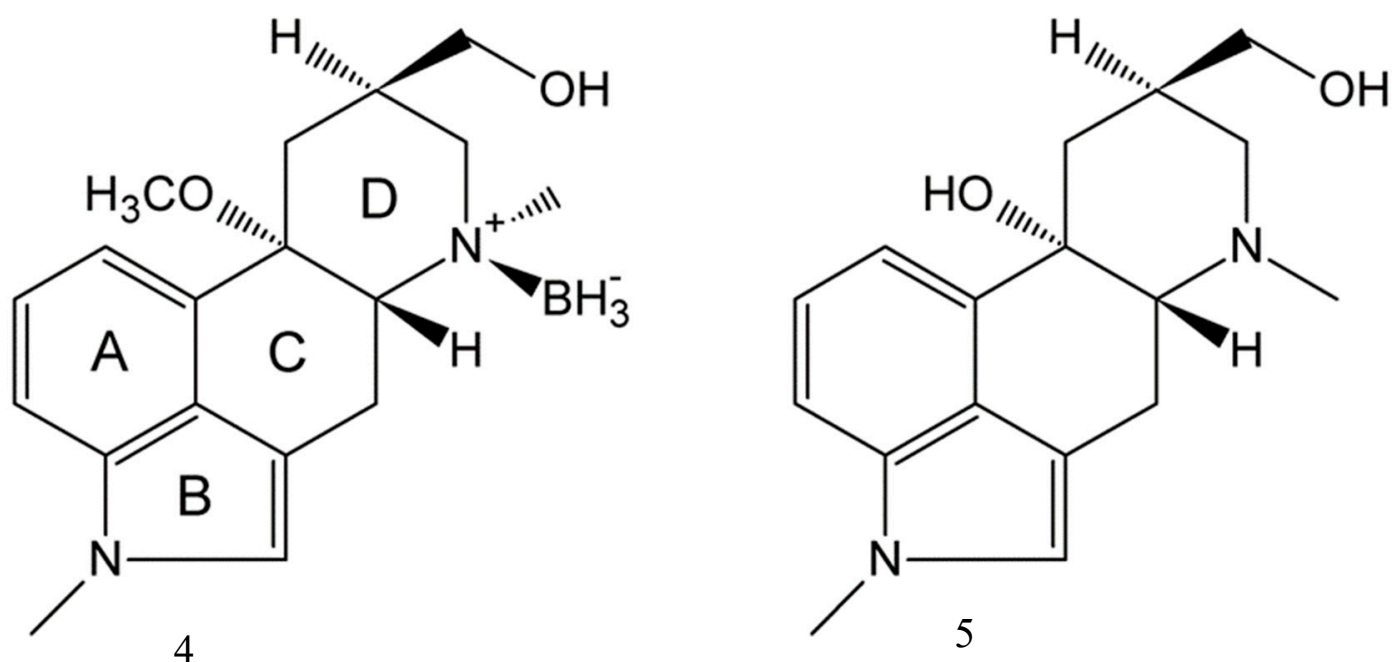

Figure 2. Scheme of $\mathrm{BH}_{3}-\mathrm{MeLuol}$ complex (4) and Luol (5). 


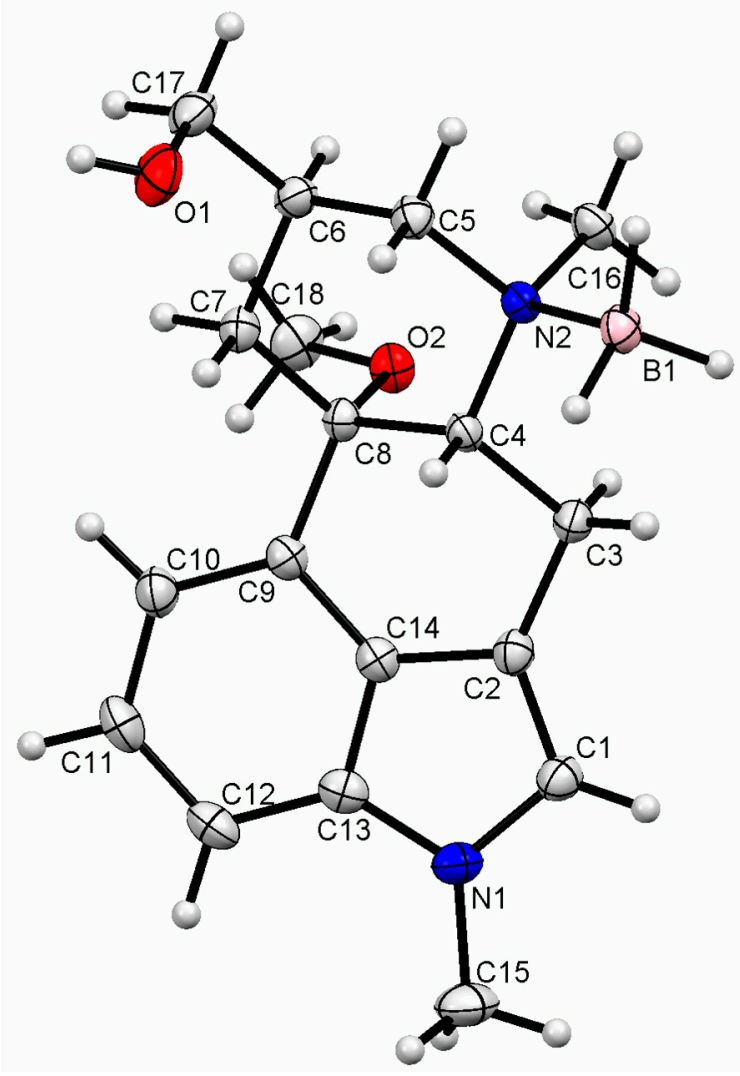

Figure 3. ORTEP drawing of $\mathrm{BH}_{3}-\mathrm{MeLuol}$ (4) with atomic numbering, ADP drawn at 50\% probability level.

\section{Dihydrogen Bond}

The dihydrogen bond is a relatively new phenomenon among weak intermolecular interactions. It is a non-conventional hydrogen bond, described by Crabtree et al. in 1996 as " $\mathrm{H}-\mathrm{H}$ or dihydrogen bond between a conventional hydrogen bond donor such as an $\mathrm{NH}$ or $\mathrm{OH}$ group as the weak acid component and an element-hydride bond as the weak base component, where the element in question can be a transition metal or boron" [9]. It is rarely mentioned in crystallography textbooks [10]. For a complete review of the dihydrogen bonding concept, see [11].

\section{Results and Discussion}

\subsection{Preparation of Single Crystals}

Powder $\mathrm{BH}_{3}-\mathrm{MeLuol}(4)(74 \mathrm{mg})$ was dissolved in ethyl formate $(7 \mathrm{~mL})$. The solution was allowed to slowly evaporate in open vial at $298 \mathrm{~K}$. Single crystals were formed within two days after the volume of the solution was reduced to about two-thirds.

\subsection{Single-Crystal X-ray Diffraction Structure}

$\mathrm{BH}_{3}$-MeLuol (4; borate(1-), trihydro-N6-(1methyl-10 $\alpha$-methoxy-9,10-dihydrolysergol(1+))) crystallizes in the orthorhombic system, space group $P 2_{1} 2_{1} 2_{1}$, one molecule in the asymmetric part of the unit cell. Full crystallographic details are given in Table 1. Please note that the systematic ergoline numbering $N 6$ corresponds to $N 2$ in the current crystal structure). 
Table 1. Crystallographic data of the structures.

\begin{tabular}{|c|c|}
\hline Empirical formula & $\mathrm{C}_{18} \mathrm{H}_{27} \mathrm{BN}_{2} \mathrm{O}_{2}$ \\
\hline Formula weight & $314.24 \mathrm{~g} / \mathrm{mol}$ \\
\hline Temperature & $180 \mathrm{~K}$ \\
\hline Wavelength & $1.54178 \AA$ \\
\hline Crystal system & Orthorhombic \\
\hline Space group & $P 2{ }_{1} 2_{1} 2_{1}$ \\
\hline Unit cell dimensions & $a=9.6759(14) \AA$ \\
\hline & $b=11.8394(16) \AA$ \\
\hline & $c=14.752(3) \AA$ \\
\hline$V$ & $1690.0(7) \AA^{3}$ \\
\hline Z & 4 \\
\hline Density (calculated) & $1.235 \mathrm{~g} / \mathrm{cm}^{3}$ \\
\hline Absorption coefficient & $0.623 \mathrm{~mm}^{-1}$ \\
\hline$F_{000}$ & 680.0 \\
\hline Crystal size & $0.152 \times 0.280 \times 0.408 \mathrm{~mm}^{3}$ \\
\hline Theta range for data collection & $4.79^{\circ}$ to $72.147^{\circ}$ \\
\hline Index ranges & $-11 \leq h \leq 11,-14 \leq k \leq 14,-17 \leq l \leq 18$ \\
\hline Reflections collected & 20314 \\
\hline Independent reflections & $3301\left[R_{\text {int }}=0.036\right]$ \\
\hline Completeness to $\theta=72.147^{\circ}$ & $99.999 \%$ \\
\hline Max. and min. transmission & 0.75 and 0.91 \\
\hline Refinement method & Full-matrix least-squares on $F^{2}$ \\
\hline Data/restraints/parameters & $3301 / 5 / 226$ \\
\hline Goodness-of-fit on $F^{2}$ & 1.001 \\
\hline Final $R$ indices $[I>2 \sigma(I)]$ & $R_{1}=0.0311, w R_{2}=0.0731$ \\
\hline$R$ indices (all data) & $R_{1}=0.0296, w R_{2}=0.0700$ \\
\hline Extinction coefficient & $189(4)$ \\
\hline Largest diff. peak and hole & 0.19 and $-0.15 \mathrm{e} \cdot \AA^{-3}$ \\
\hline Flack $x$ & $0.06(18)$ \\
\hline
\end{tabular}

\subsection{Impact of $\mathrm{BH}_{3}$ on the MeLuol Conformation}

The side product 4 is a derivative of MeLuol (3; 1-methyl-10 $\alpha$-methoxy-9,10-dihydrolysergol). The complexation of $\mathbf{3}$ with borane had a very low influence on the original molecular conformation of $3[12,13]$. An LSQ fit of the molecules was calculated in DSViewer [14] to provide an illustrative overview (Figure 4) of the particular conformations.

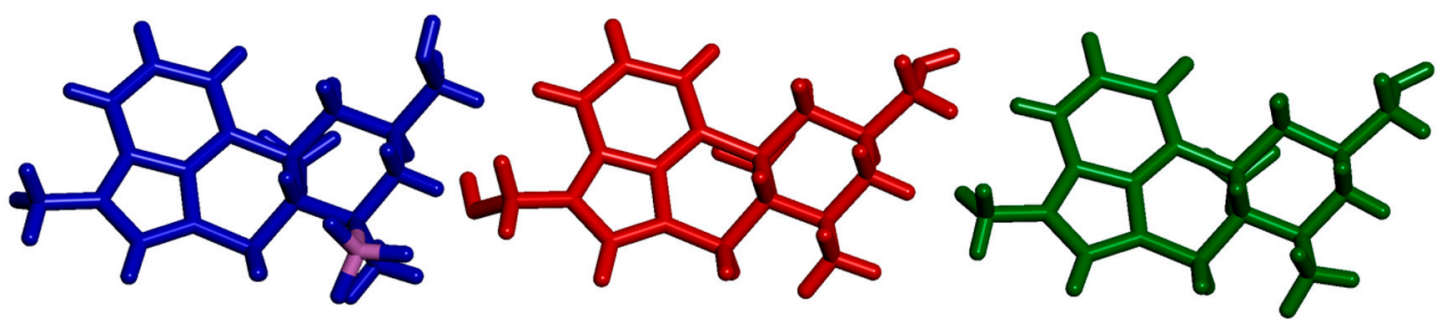

Figure 4. Parallel-oriented molecules of Luol derivatives. $\mathrm{BH}_{3}-\mathrm{MeLuol}$ (4)—blue, Luol (5)—red, MeLuol (3)-green, boron-pink.

There are three subtle differences in the molecular conformations. The hydroxymethyl group of 4 is rotated to the torsion angle of $\mathrm{C} 5-\mathrm{C} 6-\mathrm{C} 17-\mathrm{O} 1=-55.54(14)^{\circ}$. The corresponding dihedral angles are C7-C8-C20-O21 = 165.49(18) ${ }^{\circ}$ in Luol (5 = 1-methyl-10 $\alpha$-hydroxy-9,10-dihydrolysergol $)$ and C7-C8-C19-O20 $=166.29(11)^{\circ}$ for MeLuol (3). The conformational change is promoted by the change of molecular packing as the hydroxyl group binds to the same location occupied by borane in 4 and the lone pair of the tertiary amine in 3 and $\mathbf{5}$. In $\mathbf{4}$, the methyl adjacent to $N 2$ amine adopts position switched to below plane, while its site is occupied by borane. Another difference can be found in the 
conformation of ring D (see Figure 2 for the ring system lettering), which is shallower in 4 compared to 3 and 5 (Figure 5). The respective puckering amplitudes [15] of the chair conformations represent quantifications of the visual differences: 0.5359(14) $\AA$ for 4, 0.578(2) $\AA$ for 5, and 0.5792(11) $\AA$ for 3 .

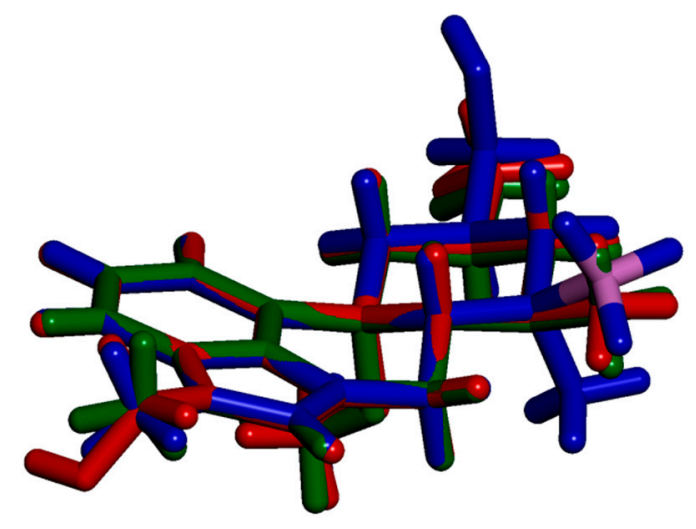

Figure 5. Side-oriented fitted molecules of Luol derivatives. $\mathrm{BH}_{3}-\mathrm{MeLuol}$ (4)—blue, Luol (5)—red, MeLuol (3)-green, boron-pink.

\subsection{Structural Features}

\subsubsection{Molecular Packing Compared to Related Derivatives}

The positions and isotropic $\mathrm{ADP}^{\prime}$ s hydrogen atoms bonded to hetero atoms $\mathrm{B}$ and $\mathrm{O}$ were refined with soft restraints.

The molecular packing and conformation were compared with related structures of 3 and 5 (CCDC code: RAXPEM, JAZPAC) [12,13].

The molecules of 4 formed infinite zigzag chains via $\mathrm{O}-\mathrm{H} \ldots \mathrm{H}_{2}-(\mathrm{HB})$ bifurcated dihydrogen bonds along the $c$-axis. The fused rings of two adjacent molecules form an angle of $51^{\circ}$. The packing was stabilized by weak $\mathrm{C}-\mathrm{H} \ldots \pi$ contacts.

In 5 , the molecules form similar infinite zigzag chains along $a$-axis using $\mathrm{O}-\mathrm{H} \ldots \mathrm{N}$ hydrogen bonds. Due to less space, the adjacent molecules are more tilted. They bind to each other in an almost perfect perpendicular arrangement. The angle between the fused rings of the neighboring molecules is $87^{\circ}$. The chains are crosslinked by an $\mathrm{O}-\mathrm{H} \ldots$ O hydrogen bond to the first $\mathrm{O}-\mathrm{H}$ group.

The molecules of $\mathbf{3}$ form virtually the same infinite zigzag chains along the $a$-axis by employing $\mathrm{O}-\mathrm{H}$... N hydrogen bonds. As in 5, due to less space, the adjacent molecules are more tilted. They bind to each other in an almost perfect perpendicular arrangement. The angle between the fused rings of the neighboring molecules is $88^{\circ}$. As there are no more hydrogen bond donors, the infinite rings are crosslinked, and crystal packing stabilized by weak $\mathrm{C}-\mathrm{H}$... O improper hydrogen bonds.

\subsubsection{Biased B-H Bonds in CSD}

There are almost no structures of pharmaceutically used aminoboranes. As the dihydrogen bond is a relatively new phenomenon [9-11,16], more effort was invested in the investigation of binding features of the borane group intermolecular binding ability.

The coordination of borane in 4 was compared to X-ray structures of similar $\mathrm{BH}_{3}-\mathrm{N}$-methylcyclohexane-containing structures (CCDC code: XANFUN, QOPGOR) $[17,18]$. For the list of $\mathrm{BH}_{3}-\mathrm{N}$ geometry, see Table 2. Under the brief inspection of the CIF data, it was clear that the B-H bond length distances of the published structures (XANFUN, QOPGOR) were set according to $\mathrm{sp}^{3}$ geometry, but the $\mathrm{B}-\mathrm{H}$ distances were erroneously fixed as equal to $\mathrm{C}-\mathrm{H}$ bond distances. Interestingly, the CSD (May 2019) contains 488 structures with $\mathrm{BH}_{3}-\mathrm{N}$ aminoboranes, when neglecting no-hydrogen and no-coordinate deposits. In 114 structures, all B-H bond lengths were smaller than $1.1 \AA$. The $d(\mathrm{~B}-\mathrm{H})$ values are $1.0 \AA$ or less for all B-H bonds in 86 structures (23 published during the last five years). 
The B-H bond length was experimentally determined as $1.190 \AA$ A by FTIR [19]. Deviations of the B-H bond length of about $0.05 \AA$ were reported, however, for terminal atoms, was about $0.1 \AA$ [20]. Investigations based on CSD data mining, e.g., [21], are inevitably based on partially biased data, and the authors highlight the inaccuracy in hydrogen atom positions. By contrast, Crabtree et al., in 1996, used normalized B-H and N-H bond distances to avoid systematic underestimation of the bond lengths in the CSD structures [9].

Table 2. Aminoborane group comparison with published results.

\begin{tabular}{ccc}
\hline Compound & $d(\mathbf{B}-\mathbf{N})(\AA)$ & $d(\mathbf{B}-\mathbf{H})(\AA)$ \\
\hline 4 & $1.6358(18)$ & $1.144-1.160(13)$ \\
QOPGOR & $1.608(4)$ & $0.96^{*}$ \\
XANFUN & $1.621(3)$ & $0.96^{*}$ \\
ABUKAJ & $1.600(3)$ & $1.154(16)$ \\
DAZPIE & $1.580(6), 1.574(5)$ & $1.057-1.155(8), 0.97-1.21(8)$ \\
DORHAV & $1.606(4)$ & $1.02-1.13(3)$ \\
DUZNUI & $1.627(3)$ & $1.14-1.18(3)$ \\
WANTAI & $1.610(4)$ &
\end{tabular}

Structures containing $\mathrm{N}-\mathrm{BH}_{3}$ groups were extracted from CSD. The observations are summarized in histograms of $\mathrm{B}-\mathrm{H}$ bond lengths in $\mathrm{N}-\mathrm{BH}_{3}$ groups giving a statistical overview of $2637 \mathrm{~B}-\mathrm{H}$ bonds (879 $\mathrm{BH}_{3}$ groups) in $488 \mathrm{CSD}$ published structures (Figure 6). Using simple criteria, the data were split to two groups: structures in which position of the $\mathrm{BH}_{3}$ hydrogen atoms were probably refined (1494 bonds in 318 structures), and structures with B-H bond distances set according to the optimal geometry or forced by strong restraints (1143 bonds in 170 structures). As the CSD does not contain standard uncertainties, the criterion-whether the $\mathrm{BH}_{3}$ hydrogen atoms were refined-was based on the difference of min. and max. $d(\mathrm{~B}-\mathrm{H})$ of each $\mathrm{BH}_{3}$ group. In general, non-refined or firmly restrained $\mathrm{BH}_{3}$ groups should have zero or very low variances of $d(\mathrm{~B}-\mathrm{H})$. The criterion was set to $0.01 \AA$ in the middle of the range of acceptable values, estimated from 0.000 to $0.020 \AA$. The histogram of all B-H bond lengths clearly showed two distinct statistical distributions with two strong maxima at 0.96-0.98 $\AA$ and 1.14-1.16 $\AA$. On the other hand, the histogram of the B-H bond lengths for the group of structures with likely refined $\mathrm{BH}_{3}$ groups had only one broad maximum at 1.14-1.16 $\AA$, and fairly low remnants of $0.96-0.98 \AA$. The average value of B-H bond length of $1.118 \AA$ for all structures was far from false values, those below $1.00 \AA$. When calculated from 318 likely refined structures, the average value was $1.144 \AA$. It should be noted that all non-refined BH3 groups were affected.

Unfortunately, the problem is likely connected to (415_ALERT_2_B Short Inter D-H..H-X) in the checkCIF/Platon IUCR validating tool [22]. "Obviously, when atoms approach closer than the sum of their van der Waals radii there must be either a missed interaction, such as a hydrogen bond, or their positions are in some way in error" [23]. On the other hand, the Platon software, which alerts for close contact, properly puts the dihydrogen bond on the list of the hydrogen bonds (CALC ALL procedure). Some authors, not aware of dihydrogen bond presence, may restrain or fix $d(\mathrm{~B}-\mathrm{H})$ in the same way and with the same values as for $\mathrm{C}-\mathrm{H}$ bonds ( $86 \mathrm{~N}-\mathrm{BH}_{3}$ groups containing CSD structures). "Many single-crystal structure analyses are currently carried out by non-experts using the available black-box software" [22]

The complete list of bond lengths, criterion setting, and statistical analysis is available in Supplementary Materials in the XLSX file. 


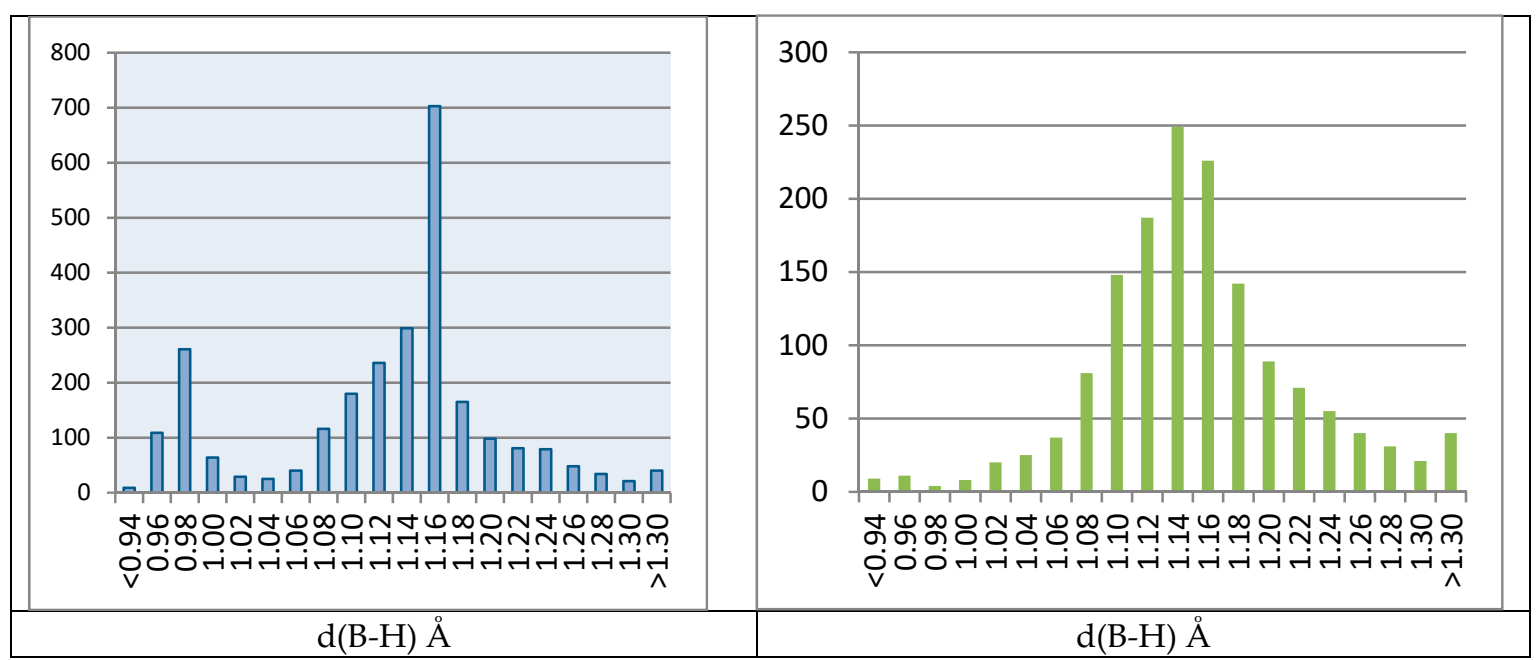

Figure 6. Histograms of bond lengths for all B-H bonds (left) and B-H bonds in probably refined $\mathrm{BH}_{3}$ groups (right).

\subsubsection{Impact of $\mathrm{BH}_{3}$ on the Molecular Packing}

Even when applying normalization of hydrogen atoms in CSD Conquest [24], the XANFUN and QOPGOR packing networks are built only by very weak improper dihydrogen bonds $\mathrm{C}-\mathrm{H} \ldots \mathrm{H}$. To find structures with hydrogen bond networks similar to 4, a search was performed for the $\mathrm{O}-\mathrm{H} \ldots$ H-B-N motif, with $d(\mathrm{H} \ldots \mathrm{H})$ limited to $2.5 \AA$. The following structures were found: ABUKAJ [25], DAZPIE [26], DORHAV [27], DUZNUI [28], and WANTAI [29]. In all five structures, the role of $\mathrm{BH}_{3}$ in stabilizing the structure via dihydrogen bonds was obvious (Table 3).

Table 3. Dihydrogen bonds connected to $\mathrm{BH}_{3}$ in similar compounds.

\begin{tabular}{|c|c|c|c|c|c|c|}
\hline $\mathbf{D}-\mathbf{H} \ldots \mathbf{A}^{*}$ & $\begin{array}{l}\text { D-H } \\
(\AA)\end{array}$ & $\begin{array}{c}\text { D ... A } \\
(\AA)\end{array}$ & $\begin{array}{c}\mathrm{H} \ldots \mathrm{A} \\
(\stackrel{\mathrm{A}}{ })\end{array}$ & $\begin{array}{c}\mathrm{D}-\mathrm{H} \ldots \mathrm{A} \\
\left({ }^{\circ}\right)\end{array}$ & $\begin{array}{c}\text { D ... B } \\
(\AA)\end{array}$ & $\begin{array}{l}\mathrm{H} \ldots \mathrm{A} \\
\left(^{\circ}\right)\end{array}$ \\
\hline \multicolumn{7}{|l|}{4} \\
\hline O1-H12 . . H14 & $0.826(15)$ & $2.983(17)$ & $2.27(2)$ & $145(2)$ & $3.3911(18)$ & \\
\hline O1-H12 . . H15 & “ & $2.809(17)$ & $2.04(2)$ & $156(2)$ & $3.3911(18)$ & $51.2(7)$ \\
\hline $\mathrm{C} 1-\mathrm{H} 11 \ldots \mathrm{H} 13$ & 0.938 & 3.184(17) & $2.398(17)$ & $141.3(3)$ & $3.605(2)$ & \\
\hline \multicolumn{7}{|l|}{ ABUKAJ } \\
\hline O17-H17O ... H18B & $0.91(3)$ & $2.881(15)$ & 2.07(4) & $148(3)$ & 3.305 & \\
\hline $\begin{array}{c}\text { O17-H17O ... H18C } \\
\text { DAZPIE }\end{array}$ & “ & $2.738(11)$ & $1.93(3)$ & $148(3)$ & “ & $56.1(10)$ \\
\hline $\begin{array}{c}\text { DAZPIE } \\
\mathrm{O} 22-\mathrm{H} 2 \ldots \mathrm{H} 1 \mathrm{~A}\end{array}$ & \\
\hline $\begin{array}{l}\mathrm{O} 22-\mathrm{H} 2 \ldots \mathrm{H} 1 \mathrm{~A} \\
\mathrm{O} 22-\mathrm{H} 2 \ldots \mathrm{H} 1 \mathrm{~B}\end{array}$ & $\underset{\mu}{0.97}$ & 3.00 & 2.14 & 147 & $3.394(9)$ & \\
\hline & “ & 2.76 & 2.11 & 122 & “ & 52 \\
\hline $\mathrm{O} 12-\mathrm{H} 1 \ldots \mathrm{H} 2 \mathrm{~A}$ & 1.12 & 2.890 & 2.28 & 112 & $3.408(8)$ & \\
\hline O12-H1 . . N21 & “ & $3.460(4)$ & 2.35 & 171 & - & 76 \\
\hline \multicolumn{7}{|l|}{ DORHAV } \\
\hline $\begin{array}{c}\text { O1-H1 . . H91 } \\
\text { DUZNUI }\end{array}$ & $0.78(3)$ & $2.80(3)$ & $2.05(4)$ & $165(3)$ & $3.249(5)$ & \\
\hline $\mathrm{O} 2-\mathrm{H} 1 \ldots \mathrm{H} 1 \mathrm{~B} 1$ & $0.89(3)$ & 2.62(2) & $1.76(4)$ & $162(3)$ & $3.498(3)$ & \\
\hline \multicolumn{7}{|l|}{ WANTAI } \\
\hline $\mathrm{O}-\mathrm{H} 10 \ldots \mathrm{H} 2 \mathrm{~B}$ & $0.88(3)$ & $2.68(2)$ & $1.81(4)$ & $173(3)$ & $3.264(3)$ & \\
\hline
\end{tabular}

${ }^{*}$ D—hydrogen bond donor, A-hydrogen bond acceptor, H-hydrogen, B-boron. For complete list of proper and improper hydrogen bonds, including ARU codes, see Supplementary Materials.

Generally, there are only small variations of structure packing. The hydrogen bond to $\mathrm{BH}_{3}$ is either single (DORHAV, DUZNUI, WANTAI) or bi-furcated (ABUKAJ, DAZPIE), similarly to the structure of 4 . 


\section{Materials and Methods}

\subsection{Single-Crystal X-ray Diffraction}

Single-crystal X-ray crystallographic diffraction data were collected at $180 \mathrm{~K}$ using a Bruker D8 Venture diffractometer equipped with $\mathrm{Cu} K \alpha$ radiation $(\lambda=1.54178 \AA)$, polycapillary monochromator, Photon 100 detector (Bruker ASX Inc., Madison, WI, USA). The habitus of the crystals could be described as parallel-oriented aggregates of pillars. The diffraction quality of the vast majority of the crystals was affected, producing diffused elongated diffraction spots that quickly lost diffraction power. Finally, a single crystal of outstanding quality was found, dipped in paraben oil, fixed to a $100 \mu \mathrm{m}$ MicroMount mounted to the goniometer head, and immediately cooled to $180 \mathrm{~K}$ for data collection. The data collection, indexing of reflections, determination of the unit cell parameters, integration of the intensity of the reflections, and frame scaling were performed using the Bruker Saint software [30]. The structure was solved by direct methods with SIR92 [31] and refined with CRYSTALS [32]. Geometry calculations including puckering parameters were conducted in Platon [22]. Molecular visualization was provided by Mercury [33] and DS Viewer [14]. The positional and atomic displacement parameters of all non-hydrogen atoms were refined. All $\mathrm{H}$ atoms were located in a difference map, but repositioned geometrically, and were then initially refined with soft restraints on the bond lengths and angles to regularize their geometry $(\mathrm{C}-\mathrm{H}$ in the range of $0.93-0.98 \AA$, $\mathrm{B}-\mathrm{H}$ to $1.15 \AA$, and $\mathrm{O}-\mathrm{H}$ to $0.82 \AA$ ) and $U_{i s o}(\mathrm{H})$ (in the range 1.2-1.5 times $U_{\text {eq }}$ of the parent atom), after which the positions of carbon-bound hydrogen atoms were refined with riding constraints. The same set of soft restraints was used during the final stages of the refinement when the positional parameters of the hetero bound hydrogen atoms were refined. The absolute configuration was resolved by the refinement of Flack $x=0.06(18)$ and the calculation of Hooft $y=0.00(7)$ parameters [34]. The chiral centers were assigned as $\mathrm{C} 4 R, \mathrm{~N} 2 \mathrm{~S}, \mathrm{C} 6 R$, and $\mathrm{C} 8 R$. The $\mathrm{C} 8$ configuration was calculated incorrectly by Platon software. The configuration of the chiral centers was in agreement with expected chirality. No additional solvent-accessible voids were found in the structure. The crystallographic data are summarized in Table 2.

CCDC 1919106 contains the supplementary crystallographic data for this paper. These data can be obtained free of charge via http://www.ccdc.cam.ac.uk/conts/retrieving.html (or from the CCDC, 12 Union Road, Cambridge CB2 1EZ, UK; Fax: +44 1223 336033; E-mail: deposit@ccdc.cam.ac.uk)

\subsection{Materials Used}

The historical source of 3: Galena Co., Opava, Czech Republic (Teva Pharmaceutical Industries Ltd., Opava, Czech Republic) Solvents were obtained from commercial sources (Sigma Aldrich, Prague, Czech Republic).

MicroMount $100 \mu \mathrm{m}$, M1-L19-S2, MiTeGen, Ithaca, NY, USA.

Parabar 10312, HR2-643, Hampton Research, Irvine, CA, USA.

\section{Conclusions}

We have crystallized and solved the crystal structure of BH3-MeLuol with a remarkable hydrogen bond network featuring a dihydrogen bond. When comparing the molecular packing to the published CSD structures, we have encountered a problem with a significant occurrence of suspiciously short B-H bond lengths in the CSD. The values resemble methyl optimal geometry. We have demonstrated the statistical relation of the false values with the absence of hydrogen atoms refinement. Surprisingly, the B-H average distance, calculated from all B-H bonds, was only slightly biased. The B-H intermolecular contacts are up to $0.2 \AA$ longer in almost $18 \%$ of the published structures, which affects statistical studies dealing with weak inter- and intramolecular interactions. A CSD user who is aware of the problem can handle it with an optional normalization of B-H lengths to at least $1.15 \AA$ as available in the Conquest search. As the source of the bias is human error, we would like to emphasize this problem. The structures containing dihydrogen bonds trigger false alerts in IUCR checkCIF (based on Platon 
software [22]) on short contacts between hydrogen atoms (415_ALERT_2_B Short Inter D-H..H-X). Some authors, not aware of the presence of the dihydrogen bond, may restrain or fix the $\mathrm{B}-\mathrm{H}$ distances in the same way and using the same values as for $\mathrm{C}-\mathrm{H}$ bonds.

We have found a group of N-BH3 containing structures in the CSD with a similar hydrogen bond network. Sometimes, likely due to its good accessibility the $\mathrm{BH}_{3}$ group can compete with the available conventional hydrogen bond acceptors.

Supplementary Materials: The supplementary materials are available online.

Author Contributions: Writing—original draft, review and editing, structure refinement, CSD mining and comparison, J.Č.; synthesis, writing — synthetic part, bulk material preparation, L.C.; data collection, writingreview and editing, S.Ž.; manuscript writing coordination and review B.K.; conceptualization, writing—original draft, review and editing, single-crystal preparation, A.J.

Funding: This work was supported by the Czech Science Foundation (GAČR) project, Grant No. 17-02836S.

Conflicts of Interest: The authors declare no conflict of interest. The funders had no role in the design of the study; in the collection, analyses, or interpretation of data; in the writing of the manuscript, or in the decision to publish the results.

\section{References}

1. Schweitzer, B.A.; Egholm, M.; Koch, T.H. Mechanistic studies of the reduction of daunomycin with sodium borohydride. Formation and reaction of borate esters. J. Am. Chem. Soc. 1992, 114, 242-248. [CrossRef]

2. Liu, Q.; Xiong, F.-J.; He, Q.-Q.; Chen, F.-E. Development of an Efficient Process for the Decomposition of the Borate Complexes Formed during the Large-Scale Synthesis of (S)-1,2,4-Butanetriol. Org. Process Res. Dev. 2013, 17, 1540-1542. [CrossRef]

3. Niedenzu, K.; Dawson, J.W. Boron-Nitrogen Compounds. III.1,2 Aminoboranes, Part 2: The B-N Bond Character in Substituted Aminoboranes. J. Am. Chem. Soc. 1960, 82, 4223-4228. [CrossRef]

4. Narayana, C.; Periasamy, M. Hydroboration of prochiral olefins with chiral Lewis base-borane complexes: Relationship to the mechanism of hydroboration. J. Chem. Soc. Chem. Commun. 1987, 1857-1859. [CrossRef]

5. Le Toumelin, J.-B.; Baboulène, M. Chiral intramolecular amine-borane complexes as reducing agents for prochiral ketones. Tetrahedron Asymmetry 1997, 8, 1259-1265. [CrossRef]

6. Burkhardt, E.R.; Matos, K. Boron Reagents in Process Chemistry: Excellent Tools for Selective Reductions. Chem. Rev. 2006, 106, 2617-2650. [CrossRef] [PubMed]

7. Hisaki, I.; Shizuki, N.; Sasaki, T.; Ito, Y.; Tohnai, N.; Miyata, M. Handedness Determination of $2{ }_{1}$ Helical Motifs and Hierarchical Analysis of Crystal Structures Based on the Motifs: The Case of Cinchona Alkaloid Derivatives. Cryst. Growth Des. 2010, 10, 5262-5269. [CrossRef]

8. Hodgkin, D.C. The X-ray Analysis of Complicated Molecules. Science 1965, 150, 979-988. [CrossRef] [PubMed]

9. Crabtree, R.H.; Siegbahn, P.E.M.; Eisenstein, O.; Rheingold, A.L.; Koetzle, T.F. A New Intermolecular Interaction: UnconventionalHydrogen Bonds with Element-Hydride Bonds as ProtonAcceptor. Acc. Chem. Res. 1996, 29, 348-354. [CrossRef] [PubMed]

10. Desiraju, G.R.; Steiner, T. The Weak Hydrogen Bond: In Structural Chemistry and Biology; International Union of Crystallography monographs on crystallography; first publ. in paperback; Oxford University Press: Oxford, UK, 2001; ISBN 978-0-19-850970-7.

11. Bakhmutov, V.I. Dihydrogen Bonds: Principles, Experiments, and Applications; Wiley-Interscience: Hoboken, NJ, USA, 2008; ISBN 978-0-470-18096-9.

12. Čejka, J.; Kratochvíl, B.; Cvak, L.; Jegorov, A. Crystal structure of 1-hydroxymethyl-10 $\alpha$-methoxy-9,10dihydrolysergol, $\mathrm{C}_{18} \mathrm{H}_{24} \mathrm{~N}_{2} \mathrm{O}_{3}$. Z. Krist. New Cryst. Struct. 2005, 220, 371-372. [CrossRef]

13. Čejka, J.; Kratochvíl, B.; Cvak, L.; Jegorov, A. Crystal structure of 1-methyl-10 $\alpha$-methoxy-9,10-dihydrolysergol, $\mathrm{C}_{18} \mathrm{H}_{24} \mathrm{~N}_{2} \mathrm{O}_{2}$. Z. Krist. New Cryst. Struct. 2005, 220, 217-218. [CrossRef]

14. Discovery Studio Modeling Environment; Dassault Systèmes BIOVIA; Dassault Systèmes: San Diego, CA, USA, 2016.

15. Cremer, D.; Pople, J.A. General definition of ring puckering coordinates. J. Am. Chem. Soc. 1975, 97, 1354-1358. [CrossRef] 
16. Flores-Parra, A.; Sánchez-Ruiz, S.A.; Guadarrama, C.; Nöth, H.; Contreras, R. BH $\delta-\delta+H C$ Interactions in N-Borane and N-Chloroborane Adducts Derived from 1,3,5-Heterocyclohexanes. Eur. J. Inorg. Chem. 1999, 1999, 2069-2073. [CrossRef]

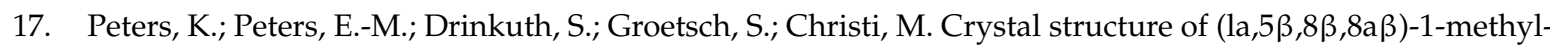
1,2,3,5,8,8a-hexahydro-5,8- epoxychinolin(N-B)boran, $\mathrm{C}_{9} \mathrm{H}_{10} \mathrm{NO}\left(\mathrm{CH}_{3}\right)\left(\mathrm{BH}_{3}\right)$. Z. Krist. New Cryst. Struct. 2000, 215, 600-602. [CrossRef]

18. Peters, E.-M.; Peters, K.; Groetsch, S.; Christi, M. Crystal structure of $(1 \alpha, 2 \beta, 8 \alpha)-2-$-methyl-8-phenyl-2azabicyclo[4.2.0] oct- 5-ene(N-B)boran, $\left(\mathrm{C}_{6} \mathrm{H}_{5}\right) \mathrm{C}_{7} \mathrm{H}_{9} \mathrm{~N}\left(\mathrm{CH}_{3}\right)\left(\mathrm{BH}_{3}\right)$. Z. Krist. New Cryst. Struct. 2001, 216, 121-122. [CrossRef]

19. Kawaguchi, K. Fourier transform infrared spectroscopy of the $\mathrm{BH}_{3} v_{3}$ band. J. Chem. Phys. 1992, 96, 3411-3415. [CrossRef]

20. Jones, D.S.; Lipscomb, W.N. Analysis of diborane X-ray diffraction data utilizing structure factors calculated from molecular wave functions. Acta Crystallogr. Sect. A 1970, 26, 196-207. [CrossRef]

21. Milovanović, M.M.; Andrić, J.M.; Medaković, V.B.; Djukic, J.-P.; Zarić, S.D. Investigation of interactions in Lewis pairs between phosphines and boranes by analyzing crystal structures from the Cambridge Structural Database. Acta Crystallogr. Sect. B Struct. Sci. Cryst. Eng. Mater. 2018, 74, 255-263. [CrossRef] [PubMed]

22. Spek, A.L. Structure validation in chemical crystallography. Acta Crystallogr. Sect. D Biol. Crystallogr. 2009, 65, 148-155. [CrossRef] [PubMed]

23. Spek, A.L. Single-crystal structure validation with the program PLATON. J. Appl. Crystallogr. 2003, 36, 7-13. [CrossRef]

24. Bruno, I.J.; Cole, J.C.; Edgington, P.R.; Kessler, M.; Macrae, C.F.; McCabe, P.; Pearson, J.; Taylor, R. New software for searching the Cambridge Structural Database and visualizing crystal structures. Acta Crystallogr. Sect. B Struct. Sci. 2002, 58, 389-397. [CrossRef] [PubMed]

25. Blakemore, P.R.; Kim, S.-K.; Schulze, V.K.; White, J.D.; Yokochi, A.F.T. Asymmetric synthesis of (+)-loline, a pyrrolizidine alkaloid from rye grass and tall fescue. J. Chem. Soc. Perkin Trans. 1 2001, 1831-1847. [CrossRef]

26. Groselj, U.; Bevk, D.; Jakse, R.; Meden, A.; Stanovnik, B.; Svete, J. CCDC 286431: Experimental Crystal Structure Determination; The Cambridge Crystallographic Data Centre: Cambridge, UK, 2006.

27. White, J.M.; McClure, M.S. CCDC 1026489: Experimental Crystal Structure Determination; The Cambridge Crystallographic Data Centre: Cambridge, UK, 2014.

28. Gainsford, G.J.; Luxenburger, A.; Woolhouse, A.D. CCDC 790649: Experimental Crystal Structure Determination; The Cambridge Crystallographic Data Centre: Cambridge, UK, 2010.

29. Pinaka, A.; Vougioukalakis, G.; Dimotikali, D.; Psyharis, V.; Papadopoulos, K. A Convenient One-Step Synthesis of Stable $\beta$-Amino Alcohol N-Boranes from $\alpha$-Amino Acids. Synthesis 2012, 44, 1057-1062. [CrossRef]

30. Apex 3, Saint; Bruker AXS Inc.: Madison, WI, USA, 2016.

31. Altomare, A.; Cascarano, G.; Giacovazzo, C.; Guagliardi, A.; Burla, M.C.; Polidori, G.; Camalli, M. SIR92-A program for automatic solution of crystal structures by direct methods. J. Appl. Cryst. 1994, $27,435$. [CrossRef]

32. Betteridge, P.W.; Carruthers, J.R.; Cooper, R.I.; Prout, K.; Watkin, D.J. CRYSTALS version 12: Software for guided crystal structure analysis. J. Appl. Cryst. 2003, 36, 1487. [CrossRef]

33. Macrae, C.F.; Bruno, I.J.; Chisholm, J.A.; Edgington, P.R.; McCabe, P.; Pidcock, E.; Rodriguez-Monge, L.; Taylor, R.; Streek, J.V.D.; Wood, P.A. Mercury CSD 2.0-New features for the visualization and investigation of crystal structures. J. Appl. Crystallogr. 2008, 41, 466-470. [CrossRef]

34. Hooft, R.W.W.; Straver, L.H.; Spek, A.L. Determination of absolute structure using Bayesian statistics on Bijvoet differences. J. Appl. Cryst. 2008, 41, 96-103. [CrossRef]

Sample Availability: Not available. 